\title{
Segmental wall motion abnormalities alter vulnerability to ventricular ectopic beats associated with acute increases in aortic pressure in patients with underlying coronary artery disease
}

\author{
K Siogas, S Pappas, G Graekas, J Goudevenos, G Liapi, D A Sideris
}

\begin{abstract}
Objective-To evaluate whether patients with coronary artery disease are susceptible to pressure related ventricular arrhythmias, and if so to identify possible risk factors.

Design-Interventional study.

Methods-Metaraminol was given to 43 patients undergoing coronary arteriography for ischaemic heart disease to increase their aortic pressure, provided their systolic blood pressure was $<160$ mm $\mathrm{Hg}$ and they were in sinus rhythm, without any ventricular ectopic activity (or with fewer than six ventricular ectopic beats a minute) during a five minute control period.
\end{abstract}

Results-During the metaraminol infusion, systolic aortic pressure rose from 131 (15) to 199 (12) mm Hg (mean (SD)). Ventricular ectopy appeared (or ventricular ectopic beats increased by $>100 \%$ ) in $13 / 43$ patients. Ventricular ectopy was not related to age, sex, presence of hypertension, history of myocardial infarction, use of $\beta$ blockers, positive exercise test, number of vessels diseased, or heart rate change during metaraminol infusion. There was a strong relation between the appearance of ventricular arrhythmia and segmental wall motion abnormalities: 1/19 (5.3\%, 95\% confidence interval $0.1 \%$ to $26.0 \%)$ without abnormality; $2 / 12(16.7 \%$, $2.1 \%$ to $48.4 \%$ ) with hypokinesia; and $10 / 12$ $(83.3 \%, 51.6 \%$ to $97.1 \%)$ with akinesia or dyskinesia, $\left.\chi^{2}=22.7, \mathrm{p}<0.001\right)$. Ejection fraction was also a significant but not independent risk factor.

Cardiology

Department, Division

of Internal Medicine,

University General

Hospital, Leoforos

Panepistimiou,

Ioannina, Greece 45500

K Siogas

S Pappas

G Graekas

J Goudevenos

G Liapi

D A Sideris

Correspondence to:

Dr Siogas.

Accepted for publication

3 November 1997

Conclusions-Patients with segmental wall motion abnormalities are predisposed to ventricular ectopic beats during an increase in systolic aortic pressure. This could be explained by associated electrophysiological inhomogeneity. The presence of mechanical inhomogeneity, as may occur in postinfarction akinesia or dyskinesia, may affect the aortic pressure above which ventricular arrhythmias appear.

(Heart 1998;79:268-273)

Keywords: mechanoelectrical feedback; segmental wall motion; akinesia; dyskinesia; ventricular ectopic beats; arrhythmias
Ventricular arrhythmias are associated with increased mortality in patients with coronary artery disease, particularly after myocardial infarction. $^{1-3}$ Several mechanisms have been proposed for these arrhythmias-for example myocardial ischaemia, ${ }^{4}$ structural myocardial inhomogeneity, ${ }^{5-7}$ left ventricular systolic dysfunction, ${ }^{12}$ metabolic abnormalities, notably hypokalaemia and hypomagnesaemia, ${ }^{89}$ neurohumoral actions, ${ }^{10}$ and the proarrhythmic effect of antiarrhythmic agents. ${ }^{11}$

Conventional antiarrhythmic treatment may actually increase mortality in spite of reducing the incidence of ectopic beats. ${ }^{12}$ On the other hand, treatment with angiotensin converting enzyme inhibitors improved survival in postinfarction patients with either overt heart failure ${ }^{13}$ or asymptomatic left ventricular dysfunction, ${ }^{14}$ as well as in patients with heart failure of different aetiology. ${ }^{15}{ }^{16}$ This beneficial effect has been attributed to haemodynamic improvement, but there is evidence that an indirect antiarrhythmic effect may also play a role. ${ }^{17-19}$ This has renewed interest in contractionexcitation feedback, which refers to electrophysiological changes or ectopic activity following or caused by mechanical changes in the myocardium. ${ }^{2021}$ Experimental and clinical trials have shown that acute pressure overload of the left or right ventricle induces ventricular ectopic activity, while pressure unloading eliminates or ameliorates pre-existing ventricular arrhythmias. ${ }^{22} 23$

The aim of this study was to evaluate whether patients undergoing routine cardiac catheterisation for coronary artery disease are susceptible to arrhythmias associated with acute increases in aortic pressure, and if so to identify possible risk factors for this susceptibility.

\section{Methods}

PATIENTS

This study was approved by the ethics committee of our institution, and all patients gave informed consent after eligibility for recruitment had been decided.

Inclusion criteria-Every patient undergoing coronary arteriography for ischaemic heart disease was eligible for recruitment into the study, provided (1) the systolic aortic pressure was less than $160 \mathrm{~mm} \mathrm{Hg}$ and (2) there was sinus rhythm without any ventricular ectopic activity or with fewer than six ventricular extrasystoles a minute during a five minute control 
Table 1 Clinical, haemodynamic, and angiographic characteristics

\begin{tabular}{ll}
\hline Age range (years) & 44 to 70 \\
Mean (SD) & $60(7)$ \\
Male/female & $39 / 4$ \\
History of hypertension & 20 \\
History of myocardial infarction & 19 \\
Use of $\beta$ blockers & 31 \\
Basal VEBs & 5 \\
Mean (SD) basal systolic BP (mm Hg) & $131(15)$ \\
Mean (SD) basal heart rate (beats/min) & $68(13)$ \\
No CAD & 7 \\
One vessel disease & 10 \\
Two vessel disease & 17 \\
Three vessel disease & 9 \\
LVEF, range (\%) & 28 to 78 \\
Mean (SD) & $57(12)$ \\
LVEDP, range (mm Hg) & 8 to 20 \\
Mean (SD) & $12(4)$ \\
LV normal contractility & 19 \\
Hypokinesia & 12 \\
Akinesia-dyskinesia & 12
\end{tabular}

$\mathrm{BP}$, blood pressure; CAD, coronary artery disease; LVEDP, left ventricular end diastolic pressure; LVEF, left ventricular ejection fraction; VEB, ventricular ectopic beats.

period on completion of the routine catheterisation procedure.

Exclusion criteria-Exclusion criteria were: use of antiarrhythmic drugs except for $\beta$ blockers; a history of stroke or any other intracerebral disease; congestive heart failure or an end diastolic pressure $>20 \mathrm{~mm} \mathrm{Hg}$; a history of any major myocardial ischaemic event during the past three months; valvar or pericardial disease; left main stem disease; and any complication during catheterisation.

Forty three patients were finally examined; 22 other patients who were catheterised did not fulfil the inclusion criteria; 63 were excluded because of the exclusion criteria.

Recruitment of the patients continued until a statistically clear result was obtained. Because of the small number of cases with dyskinesia (three patients), these were put in the akinesia group.

\section{PROCEDURES}

Routine coronary angiography was performed in all patients using the Judkins technique. Left ventriculography was performed in two projections, right anterior oblique $30^{\circ}$ and left anterior oblique $60^{\circ}$. Following left ventriculography, the catheter was withdrawn to the descending thoracic aorta. After a rest period of about five minutes the aortic pressure was recorded on a Mennen Horizon 2000 instrument (Mennen Medical, Clarence, New York, USA), along with a three lead ECG, at a chart speed of $5 \mathrm{~mm} / \mathrm{s}$. After a five minute control period, an intravenous infusion of metaraminol hydrochloride, an agent with predominantly $\alpha$ adrenergic activity, ${ }^{24}$ was given at a rate of 1 $\mathrm{mg} / \mathrm{min}$, while the patient's electrocardiogram and aortic pressure were recorded continuously. The infusion was stopped when: (a) the systolic aortic pressure increased to $200 \mathrm{~mm} \mathrm{Hg}$; (b) the patient complained of chest pain, dyspnoea, headache, or developed ST segment abnormalities on the electrocardiogram; or (c) ventricular extrasystoles appeared in patients without ectopy in the control period (or, for patients with ventricular extrasystoles during the control period, if they showed an increase of at least $100 \%$ ). In cases where ventricular ectopic activity developed, the metaraminol test was considered positive.

Every week the coronary angiography and ventriculography data were assessed visually by three experienced invasive cardiologists who determined by consensus the number of stenosed vessels and the severity of the lesion. Stenoses of more than $50 \%$ of the luminal diameter in two orthogonal projections were considered significant. At the same time the presence of segmental wall motion abnormalities was assessed in the two projections by one investigator, who ignored the result of the metaraminol test. The endocardial silhouette was drawn in each projection for both end diastolic and end systolic frames, which were then superimposed on their long axes and divided into seven segments ${ }^{25}$ : anterobasal, anterolateral, apical, diaphragmatic, posterobasal (right anterior oblique projection), lateral, and septal (left anterior oblique projection). The systolic change in length of each of these segments was expressed as per cent of the corresponding end diastolic length. The systolic movement of each segment was graded as follows: normal if the change in all segments was of the same order; hypokinesia if the change in one was less than that in the others; akinesia if one or more segments presented no difference between systole and diastole; and dyskinesia if one segment presented lengthening instead of shortening during systole. The ejection fraction was measured according to the Dodge's two plane area-length method. ${ }^{26}$

The incidence of a positive versus a negative metaraminol test was related to the following variables: sex, age, history of previous myocardial infarction, history of hypertension, use of $\beta$ blockers, left ventricular end diastolic pressure, basal and postmetaraminol systolic aortic pressure and heart rate values, dose of metaraminol infused, presence and number of coronary arteries with stenoses greater than $50 \%$ of the lumen diameter, left ventricular ejection fraction, and presence and degree of left ventricular segmental systolic abnormalities.

\section{STATISTICS}

Non-parametric comparisons were performed by the $\chi^{2}$ test using the Yates correction, while for parametric comparisons the paired or independent Student $t$ test was used as appropriate. Percentages are given with 95\% confidence intervals. Analysis of variance (ANOVA) was performed whenever needed. A $p$ value of $<0.05$ was considered significant. Values are given as mean (SD).

\section{Results}

Forty three patients (39 male, four female) were recruited for the study. Nineteen had a history of myocardial infarction which had occurred over three months before, 20 had a history of hypertension, and 31 were using $\beta$ blocking agents for various clinical indications. During the control period 38 patients had no ventricular ectopy, while five had single extrasystoles at an incidence of two to five per minute. Angiographically significant coronary 
Table 2 Differences in parametric variables between a positive and a negative metaraminol test

\begin{tabular}{llll}
\hline & Negative $(n=30)$ & Positive $(n=13)$ & $p$ Value \\
\hline Age (years) & $59.5(6.6)$ & $61.2(7.9)$ & NS \\
Basal SBP (mm Hg) & $132.8(15.3)$ & $126.5(15.1)$ & NS \\
Postinfusion SBP (mm Hg) & $203.1(5.7)$ & $189.8(17.7)$ & $<0.02$ \\
Basal HR (beats/min) & $66.1(11.5)$ & $72.5(16.7)$ & NS \\
Postinfusion HR (beats/min) & $53.1(10.9)$ & $64.8(17.5)$ & $<0.05$ \\
HR change (beats/min) & $13(2.3)$ & $7.7(13.4)$ & NS \\
LVEF (\%) & $61.9(8.7)$ & $44.5(9.1)$ & $<0.0009$ \\
LVEDP (mm Hg) & $11.7(3.9)$ & $12.5(4.2)$ & NS \\
\hline
\end{tabular}

EDP, end diastolic pressure; LVEF, left ventricular ejection fraction; HR, heart rate; SBP, systolic blood pressure.

Table 3 Differences in the incidence of non-parametric variables between the two groups (positive and negative metaraminol test)

\begin{tabular}{lccl}
\hline & Negative $(n=30)$ & Positive $(n=13)$ & $p$ Value \\
\hline Male sex $(\mathrm{n}=39)$ & 28 & 11 & $\mathrm{NS}$ \\
Hypertension $(\mathrm{n}=20)$ & 12 & 8 & $\mathrm{NS}$ \\
History of MI $(\mathrm{n}=19)$ & 10 & 9 & $\mathrm{NS}$ \\
Use of $\beta$ blockers $(\mathrm{n}=31)$ & 22 & 9 & $\mathrm{NS}$ \\
Positive ET $(\mathrm{n}=25)$ & 20 & 5 & $\mathrm{NS}$ \\
Normal coronary vessels & 6 & 1 & $\mathrm{NS}$ \\
One vessel disease & 8 & 2 & $\mathrm{NS}$ \\
Two vessel disease & 11 & 6 & NS \\
Three vessel disease & 5 & 4 & 0.0001 \\
Normal LV movement $(\mathrm{n}=19)$ & 18 & 1 & \\
Hypokinesia (n=12) & 10 & 2 & \\
Akinesia-dyskinesia $(\mathrm{n}=12)$ & 2 & 10 & \\
\hline
\end{tabular}

ET, exercise test; LV, left ventricular; MI, myocardial infarction.

artery disease was found in 36 patients (84\%). The clinical, haemodynamic, and angiographic characteristics of the patients are given in table 1 .

METARAMINOL INFUSION

The metaraminol infusion was not associated with severe adverse effects in any of the patients. Three of 43 complained of mild headache, one of dyspnoea, and one of chest pain without ECG findings suggesting myocardial ischaemia. All these adverse effects resolved within less than three minutes after the infusion was stopped. The dose of metaraminol infused was $7.2(2.2) \mathrm{mg}$. The systolic aortic pressure rose from 131 (15) to 199 (12) $\mathrm{mm} \mathrm{Hg}$, diastolic aortic pressure from 66 (10) to 86 (9) $\mathrm{mm} \mathrm{Hg}$, and mean aortic pressure from 91 (10) to 124 (12) $\mathrm{mm} \mathrm{Hg}$. Heart rate decreased from 68 (13) to 56 (14) beats $/ \mathrm{min}(\mathrm{p}<0.002)$, although in five patients it was increased.

The metaraminol infusion caused an arrhythmogenic response in 13 of 43 patients; of the 38 patients without any ventricular ectopy during the control period, 10 developed ventricular extrasystoles, and 28 did not. The ectopic beats induced were single extrasystoles in six of 10 patients, pairs in two of 10 , and runs in two of 10 , while the total number of ventricular extrasystoles ranged from one to 100. Of the five patients with ventricular extrasystoles during the control period, the incidence of the extrasystoles did not change in two, while it increased by $100 \%$ or more in three. In addition, the extrasystoles converted from unifocal to multifocal in two of these patients. Tables 2 and 3 show the differences in the variables examined between the patients with a positive and negative metaraminol test.

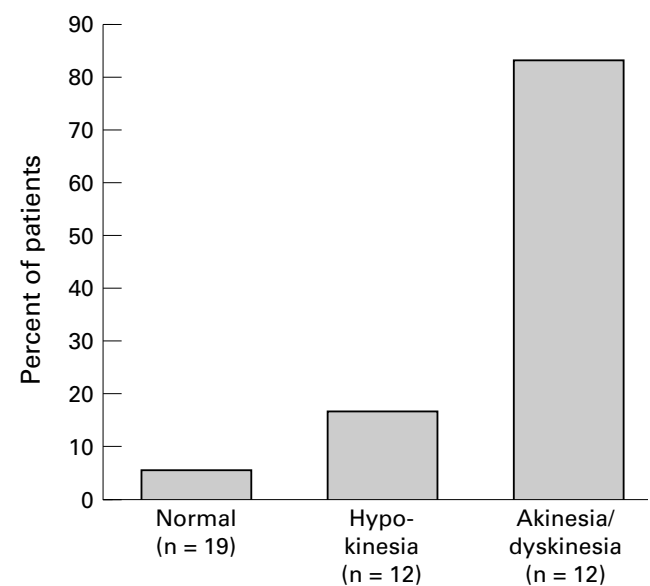

Figure 1 Incidence of pressure related arrhythmias as a function of regional kinetic abnormalities.

The systolic aortic pressure at the time of the arrhythmogenic response ranged from 135 to $200 \mathrm{~mm} \mathrm{Hg}$ (mean (SD) 169 (24)); the increase was less in patients with a positive response (189.7 (17.7)) than in those with a negative response $(203.1(5.7), \mathrm{p}<0.02)$. The postmetaraminol infusion heart rate was higher $(\mathrm{p}<0.05)$ in the patients with an arrhythmogenic response to the metaraminol test than in those without a response, at 72.5 (16.7) $v$ $66.1(11.5)$ beats $/ \mathrm{min}$. The ejection fraction in the patients with a positive metaraminol test was less $(p<0.001)$ than in those with a negative test, at $44.5(8.7) \% \quad v 61.9(8.7) \%$. The more severe the segmental wall motion abnormalities the higher was the probability of developing ventricular arrhythmias on raising the aortic pressure $\left(\chi^{2}=22.7, p<0.001\right.$ for two degrees of freedom (fig 1, table 3)). Thus ventricular ectopics or runs were induced in one of 19 patients with normal wall motion (5.3\%, 95\% confidence interval $0.1 \%$ to $26.0 \%)$, two of 12 with hypokinesia $(16.7 \%$, $2.1 \%$ to $48.4 \%$ ), and 10 of 12 with akinesia or dyskinesia $(83.3 \%, 51.6 \%$ to $97.1 \%)$. The more severe the segmental wall motion abnormalities the lower was the ejection fraction: $42.3(7.5) \%$ for dyskinesia or akinesia, $60.2(4.5) \%$ for hypokinesia, and 63.5(9.3)\% for normokinesia; $p<0.001$ for two degrees of freedom in one way ANOVA, the ejection fraction in dyskinesia/akinesia being significantly lower than in the other two categories.

Using two way ANOVA, the probability of a positive metaraminol test was significantly related to the presence of segmental wall motion abnormalities and not to the ejection fraction $(p<0.012)$, indicating that the ejection fraction is not an independent risk factor for the genesis of aortic pressure related ventricular arrhythmias. Thus the most powerful predictor of aortic pressure related arrhythmogenesis was the presence of segmental akinesia-dyskinesia (fig 1). On the other hand, age, sex, hypertension, stress induced ischaemia, use of $\beta$ blockers, basal values of aortic pressure and heart rate, and the presence and number of stenosed coronary arteries were not significantly different in patients with a positive and a negative response to the metaraminol 
test. The dose of metaraminol (and hence the time of infusion) was similar among patients with a positive and a negative metaraminol test, at $6.9(2.4)$ v $7.2(1.8) \mathrm{mg}$, respectively; $\mathrm{t}=0.24$, NS.

\section{Discussion}

To our knowledge our study is the first to examine the effect of acute blood pressure elevation on ventricular ectopics in a discrete group of patients, namely those undergoing cardiac catheterisation for evaluation of known or suspected coronary artery disease. Also, it is the first study to investigate the relation between several clinical, haemodynamic, and angiographic variables on pressure related ventricular arrhythmias.

Acute elevation of aortic pressure caused by an intravenous infusion of metaraminol induced or exaggerated ventricular ectopic activity in 13 of 43 patients $(30 \%)$. The main feature of this subgroup was the presence of left ventricular segmental wall abnormalities, particularly akinesia or dyskinesia. Global left ventricular systolic dysfunction was also more common in these patients, but it was not an independent factor. In contrast, left ventricular end diastolic pressure-a rough index of ventricular diastolic function-was similar in the two groups. Interestingly, a history of myocardial infarction was not a determining factor, indicating that the presence of small fibrotic areas in the ventricular wall without severe disturbance of systolic function is not a risk factor for pressure related arrhythmias. The two groups (with and without pressure induced ventricular ectopic beats) did not differ in any other respect, including age, gender, hypertension, basal aortic pressure and heart rate, use of $\beta$ blockers, severity of coronary artery disease, metaraminol dose, or the presence of myocardial ischaemia (as evidenced by the absence of ischaemic ECG changes during the test and no difference in stress induced myocardial ischaemia).

The arrhythmogenic effect of metaraminol seen in these cases could have been caused by pressure elevation (mechanoelectrical phenomenon) or by a direct pharmacological action of metaraminol, myocardial ischaemia, or sympathetic stimulation. Metaraminol infusion without pressure elevation is not arrhythmogenic, however. Reducing aortic pressure by arterial bleeding ${ }^{22}$ or by sucking the ventricles into a cup ${ }^{27}$ in experiments where the animal was on a continuous metaraminol drip was associated with disappearance of ventricular arrhythmias that had appeared during the metaraminol induced blood pressure elevation. Given that no patient developed ECG disturbances suggesting myocardial ischaemia during metaraminol infusion, and that the incidence of a positive exercise test did not differ between the two groups (with and without induced ventricular ectopy), myocardial ischaemia does not seem to be the explanation for the metaraminol induced arrhythmias. Furthermore, there are experimental data showing that arrhythmias produced by clamping the aortic valve are associated with an increase in coronary sinus blood flow. ${ }^{28}$ Similarly, the mechanism of these pressure related arrhythmias does not seem to be related to adrenergic activity since there was no difference between those using $\beta$ blocking agents and those who were not. Thus the only conceivable explanation that remains valid seems to be mechanoelectrical association.

The level of systolic aortic pressure above which ventricular ectopics developed (or became exaggerated) was not greater than found under physiological circumstances during strenuous physical activity (140 to $200 \mathrm{~mm} \mathrm{Hg}$, mean (SD) $=170$ (23) $\mathrm{mm} \mathrm{Hg}$ ). The emergence of arrhythmias in some cases was not a reflection of a higher aortic pressure than in the cases where arrhythmias were not induced; in fact in the former the maximum pressure reached was lower than in the latter, presumably because the metaraminol drip was stopped earlier because of the appearance of the arrhythmia.

The arrhythmogenic effect of an acute rise in blood pressure is known from previous experimental and clinical studies. ${ }^{22}{ }^{23}$ Nevertheless, the critical arrhythmogenic level of blood pressure was widely variable in those studies, often being at values outside the normal range and influenced by unknown factors. Our study suggests that a group of patients with known susceptibility to ventricular arrhythmias is vulnerable to pressure related arrhythmias. It seems likely that aortic pressure related arrhythmias may contribute in part to the high incidence of ventricular arrhythmias in these patients. Ventricular arrhythmias in patients with left ventricular systolic dysfunction are a difficult therapeutic problem given the high risk of sudden death ${ }^{29-31}$ and the failure of antiarrhythmic drugs to improve survival. ${ }^{12}{ }^{32} 33$ An explanation for the failure of antiarrhythmic treatment may be the fact that these arrhythmias are related to mechanical dysfunction of the left ventricle. On the other hand, treatment with drugs that decrease the load on the heart has resulted in a reduction in mortality in patients with heart failure $^{1516}$ and after myocardial infarction. ${ }^{1314}$ Moreover, the use of angiotensin converting enzyme inhibitors decreases ventricular $\operatorname{arrhythmias}^{17-19}$ and sudden death ${ }^{13}{ }^{19}$ in patients with heart failure, suggesting that unloading the heart has an antiarrhythmic effect.

Our results are in agreement with previous studies on the arrhythmogenic effect of acute aortic pressure elevation, and indicate that there is a group of patients who are particularly susceptible to ventricular ectopy from this mechanism. Although the mechanism of pressure related arrhythmias cannot be determined from our data, mechanoelectrical feedback is a likely possibility. The most widely studied electrophysiological effect of changes in mechanical loading is the duration of the monophasic action potential or refractoriness. ${ }^{34}$ The effect of mechanical loading on refractoriness may be variable, depending on several factors, ${ }^{21}{ }^{35-58}$ although in most studies it has been found to be shortened by increases in pressure or volume load. ${ }^{47-58}$ These discrepancies may be 
attributed to several factors such as differences in the species or tissues used, differences in the nature of the load or the phase when the load was applied, or the method of measurement involved.

Taggart et $a l^{35}$ examined the effect of acute heart load changes on the duration of the monophasic action potential of the left ventricle in 23 patients undergoing routine cardiac catheterisation. The monophasic action potential was recorded from the left ventricular endocardium - as a measure of the time course of local repolarisation-during the strain (ventricular unloading) and release (ventricular loading) phases of the Valsalva manoeuvre. In patients with normal ventricles, and even in those with a previous myocardial infarct, the monophasic action potential shortened during the strain phase and lengthened during the release phase. In patients with regional wall motion abnormalities the change of action potential duration during the Valsalva manoeuvre was often in the opposite direction, indicating a local inhomogeneity of repolarisation. In the authors' opinion, these changes in regional endocardial repolarisation caused by ventricular systolic function segmental abnormalities are a manifestation of mechanoelectrical feedback and could explain the association between ventricular arrhythmias and impaired ventricular function. The mechanical inhomogeneity, which is greatest in akinesia or dyskinesia and least in normokinesia, might be intensified by pressure elevation causing electrical inhomogeneity and arrhythmogenesis. Although it is not known whether in this study the action potential was measured in the normal or abnormal myocardium in patients with systolic segmental abnormalities, the findings suggest that adjacent normal and abnormal myocardium (as in our patients) may intensify an inhomogeneity of depolarisation of the left ventricle, causing arrhythmias. Thus, although electrical inhomogeneity unmasked by an increase in pressure seems a plausible explanation for pressure related arrhythmias, direct evidence for this is still lacking. In Taggart's patients, ${ }^{35}$ as in ours, there was no difference in response between those receiving $\beta$ blockers and those who were not, suggesting that the effect of sympathetic stimulation on arrhythmogenesis in these patients was minimal, if any.

Although the physiological increases in aortic pressure may involve different mechanisms from those operating during a pharmacological pressure increase, it is possible that ventricular arrhythmias occurring during physical effort in patients with left ventricular systolic dysfunction caused by ischaemic heart disease may at least in part be pressure related. Thus it would seem reasonable to consider the use of antihypertensive rather than antiarrhythmic agents for the management of ventricular arrhythmias in such patients. Further study of this possibility is warranted.

CONCLUSION

Our study suggests that the presence of mechanical inhomogeneity, as may occur in postinfarction akinesia or dyskinesia, may affect the aortic pressure above which ventricular arrhythmias may appear.

1 Ruberman W, Weinblatt E, Goldberg JD, et al. Ventricular premature complexes and mortality after myocardial premature complexes and mortality
infarction. N Engl F Med 1977;297:750-7.

2 Bigger JT, Fleiss JL, Kleiger R, et al for the Multicenter Post-Infarction Group. The relationships among ventricular arrhythmias, left ventricular dysfunction and mortality in the 2 years after myocardial infarction. Circulation 1984; 69:250-8

3 Kostis JB, Byington R, Friedman LM, et al. Prognostic significance of ventricular ectopic activity in survivors of acute myocardial infarction. f Am Coll Cardiol 1987;10:231-42.

4 Minisi AJ, Mukharji J, Rehr RB, et al. Association between extent of coronary artery disease and ventricular premature beat frequency after myocardial infarction. Am Heart 7 1988;115:1198-201.

5 El-Sherif N, Smith RA, Evans K. Canine ventricular arrhythmias in the late myocardial infarction period: epicardial mapping of reentrant circuits. Circ Res 1981;49: 255-65.

6 Mehra R, Zeiler RH, Gough WB, et al. Reentrant ventricular arrhythmias in the late myocardial infarction period: electrophysiologic-anatomic correlation of re-entrant cirelectrophysiologic-anatomic corr

7 De Bakker JMT, Van Capelle FJL, Janse MJ, et al. Reentry as a cause of ventricular tachycardia in patients with chronic ischaemic heart disease: electrophysiologic and anatomic correlation. Circulation 1988;77:589-606.

8 Stewart DE, Ikram H, Espiner EA, et al. Arrhythmogenic potential of diuretic induced hypokalaemia in patients with mild hypertension and ischaemic heart disease. Br Heart $\mathcal{f}$ 1985;54:290-7.

9 Packer M, Gottlieb SS, Blum MA. Immediate and long-term pathophysiologic mechanisms underlying the genesis of sudden cardiac death in patients with congestive heart failure. Am $\mathcal{F}$ Med 1987;82:4-10.

10 Francis GS. Neurohumoral mechanisms involved in congestive heart failure. Am $\mathcal{F}$ Cardiol 1985;55:15-21A.

11 Zipes DP. Proarrhythmic effects of antiarrhythmic drugs. Am f Cardiol 1987;59:26-31E.

12 The Cardiac Arrhythmia Suppression Trial (CAST) Investigators. Preliminary report: effect of encainide and flecainide on mortality in a randomized trial of arrhythmia suppression after myocardial infarction. $N$ Engl $\mathcal{F}$ Med 1989;321:406-12.

13 AIRE (Acute Infarction Ramipril Efficacy) Study Investigators. Effect of ramipril on mortality and morbidity of survivors of acute myocardial infarction with clinical evidence of heart failure. Lancet 1993;342:821-8.

14 Pfeffer MA, Brawnwald E, Moye LA, et al, on behalf of the SAVE Investigators. Effect of captopril on mortality and morbidity in patients with left ventricular dysfunction after myocardial infarction. Results of the Survival and Ventricular Enlargement Trial. $N$ Engl f Med 1992;327:669-77.

15 CONSESUS Trial Study Group. Effects of enalapril on mortality in severe congestive heart failure. Results of the cooperative North Scandinavian Enalapril Survival Study (CONSESUS). N Engl f Med 1987;316:1429-35.

16 SOLVD Investigators. Effect of enalapril on survival in patients with reduced left ventricular ejection fractions and patients with reduced left ventricular ejection fractions and
congestive heart failure. N Engl f Med 1991;325:293-302.

7 Cleland JGF, Dargie HJ, Hodsman GP, et al. Captopril in heart failure. A double blind controlled trial. Br Heart $\mathfrak{f}$ heart failure. A

18 Webster MWI, Fitzpatrick MA, Nicholls MG, et al. Effect of enalapril on ventricular arrhythmias in congestive heart failure. Am F Cardiol 1985;56:566-9.

9 Fletcher RD, Cintron GB, Johnson G, et al. Enalapril decreases prevalence of ventricular tachycardia in patients with chronic congestive heart failure. Circulation 1993; 87(suppl VI):V149-55.

20 Lab MJ. Contraction-excitation feedback in myocardium: physiological basis and clinical relevance. Circ Res 1982;50: 757-66.

21 Dean JW, Lab MJ. Arrhythmia in heart failure: role of mechanically induced changes in electrophysiology. Lancet 1989;i:1309-12.

22 Sideris DA, Chrysos DN, Maliaras GK, et al. Effect of acute hypertension on the cardiac rhythm. Experimental obserhypertension on the cardiac rhythm. Exp

23 Sideris DA, Kontoyannis DA, Michalis L, et al. Acute changes in blood pressure as a cause of cardiac arrhythchanges in blood pressure as a
mias. Eur Heart 7 1987;8:45-52.

24 Reynolds JEF, Parfitt K, Parnsons AV, et al. In: Martindale. The extra pharmacopoeia, 13th ed. London: The Pharmaceutical Press, 1993:1248.

25 Sniderman AD, Marpole D, Fallen EL. Regional contraction patterns in the normal and ischemic left ventricle in man. Am f Cardiol 1973;31:484-90.

26 Dodge HT, Sheehan FH. Quantitative contrast angiography for assessment of ventricular performance in heart disease. 7 Am Coll Cardiol 1983;1:73-9.

27 Sideris DA, Pappas S, Siongas K, et al. Effect of preload and afterload on ventricular arrhythmogenesis. $\mathcal{F}$ Electrocardiol 1995;28:147-52.

28 Sideris DA, Toumanidis ST, Kostis EB, et al. Arrhythmogenic effect of high blood pressure: some observations mogenic effect of high blood pressure: some observas

29 Weaver WD, Lorch GS, Alvarez HA, et al. Angiographic findings and prognostic indicators in patients resuscitated findings and prognostic indicators in patients res
from cardiac death. Circulation 1976;54:895-900. 
30 Schultz RA, Strauss HW, Pitt B. Sudden death in the year following myocardial infarction: relation to ventricular premature contractions in the late hospital phase
tricular function. Am $\mathcal{F}$ Med 1977;62:192-9.

31 White HD, Norris RN, Brown MA, et al. Left ventricular end systolic volume as the major determinant of survival after recovery from myocardial infarction. Circulation 1987;76:44-51

32 The Cardiac Arrhythmia Suppression Trial II Investigators. Effect of the antiarrhythmic agent moricizine on survival after myocardial infarction. N Engl 7 Med 1992;327:22733.

33 Teo KK, Yusuf S, Furberg CD. Effect of antiarrhythmic therapy on mortality following myocardial infarction [abstract]. Circulation 1990;82(suppl 3):197.

34 Sideris DA. High blood pressure and ventricular arrhythmias. Eur Heart 7 1993;14:1548-51.

35 Taggart P, Sutton P, John R, et al. Monophasic action potential recordings during acute changes in ventricular loading induced by the Valsalva manoeuvre. Br Heart $\mathcal{f} 1992 ; 67$ : 221-9.

36 Benditt DG, Kriett JM, Tobler HG, et al. Electrophysiological effects of transient aortic occlusion in intact canine heart. Am f Physiol 1985;249:1014-23.

37 Coulshed DS, Cowan JC, Drinkhill MJ, et al. The effects of ventricular end-diastolic and systolic pressures on action potential and duration in anaesthetized dogs. $\mathcal{F}$ Physiol (Lond) 1992;457:75-91

38 Denardo J, Stevenson WG. Is the adaptation of right ventricular refractoriness to an abrupt increase in heart rate impaired in chronic heart failure? Am Heart 7 1989;117: 585-9.

39 Gornick CC, Tobler HG, Pritzker MC, et al. Electrophysiologic effects of papillary muscle traction in the intact heart. Circulation 1986;73:1013-21.

40 Klein LS, Miles WM, Zipes DP. Effect of atrioventricular interval during pacing or reciprocating tachycardia on atrial
size, pressure, and refractory period. Contractionsize, pressure, and refractory period. Contraction60-8.

41 Taggart P, Sutton PMI, Treasure T, et al. Monophasic action potentials at discontinuation of cardiopulmonary bypass: evidence for contraction-excitation feedback in man. Circulation 1988;77:1266-75.

42 Yano K, Mitsuoka T, Hirata T, et al. Effect of rapid elevation of left ventricular systolic pressure on ventricular arrhyth mogenicity in the dog with old myocardial infarction [abstract]. Eur Heart $\mathcal{F}$ 1991;12:43.

43 Dominguez G, Fozzard HA. Effect of stretch on conduction velocity and cable properties of cardiac Purkinje fibers. $A m$ f Physiol 1979;237:C119-24

44 Hansen DE Craig CS, Hondenghem LM. Stretch-induced arrhythmias in the isolated canine ventricle. Evidence for the importance of mechanoelectrical feedback. Circulation 1990;81:1094-105.

45 Sideris DA, Toumanidis ST, Kostopoulos KG, et al. Effect of changes in pressure on the refractory period of the ventricles [in Greek]. Hellenic Cardiol Rev 1992;33:414-21.

46 Antoniou A, Milonas D, Kanakakis J, et al. Contractionexcitation feedback in human atrial fibrillation. Clin Cardiol 1997;20:473-6.

47 Calkins H, Maughan WL, Weisman HF, et al. Effect of acute volume load on refractoriness and arrhythmia development in isolated, chronically infarcted canine hearts. Circulation 1989;79:687-97.

48 Dean JW, Lab MJ. Regional changes in ventricular excitability during load manipulation of the in situ pig heart. $\mathcal{F}$ Physiol (Lond) 1990;429:387-400.

49 Franz R, Burkhoff D, Yue DT, et al. Mechanically induced action potential changes and arrhythmia in isolated and in situ canine hearts. Cardiovasc Res 1989;25:637-44.

$50 \mathrm{Lab}$ MJ. Mechanically dependent changes in action potentials recorded from the intact frog ventricle. Circ Res 1978;42:519-28.

$51 \mathrm{Lab}$ MJ. Transient depolarization and action potential alterations following mechanical changes in isolated myocardium. Cardiovasc Res 1980;14:624-37.

52 Lerman BB, Burkhoff D, Yue DT, et al. Mechanoelectric feedback: independent role of preload and contractility in modulation of canine ventricular excitability. $\mathcal{f}$ Clin Invest 1985;76:1843-50.

53 Levine JH, Guarnieri T, Kadish AH, et al. Changes in myocardial repolarization in patients undergoing balloon valvuloplasty for congenital pulmonary stenosis: evidence for contraction-excitation feedback in humans. Circulation 1988;77:70-7.

54 Martin GR, Stanger P. Transient prolongation of the QTc interval after balloon valvuloplasty and angioplasty in children. Am 7 Cardiol 1986;58:1233-5.

55 Reiter MJ, Synhorst DP, Mann DE. Electrophysiological effects of acute ventricular dilatation in the isolated rabbit heart. Circ Res 1988;62:554-62.

56 Spear JF, Moore EN. Stretch-induced excitation and conduction disturbances in the isolated rat myocardium. $\mathcal{F}$ Electrocardiol 1972;5:15-24.

57 Sutton PMI, Taggart P, Lab MJ, et al. Opposite electrophysiological response of human epicardium to endocardium in response to altered ventricular loading? [abstract] Eur Heart f 1992;13:246.

58 Yamashita $\mathrm{T}$, Inoue $\mathrm{H}$, Usui $\mathrm{M}$, et al. Acute effect of percutaneous transluminal mitral commissurotomy on QT interval: possible role of afterload in contraction-excitation feedback. Am Heart F 1991;121:1634-9. 